Sharif University of Technology
Scientia Iranica
Transactions E: Industrial Engineering
http://scientiairanica.sharif.edu

\title{
A goal programming capital budgeting model under uncertainty in construction industry
}

\author{
S. Etemadi, H. Koosha*, and M. Salari \\ Department of Industrial Engineering, Faculty of Engineering, Ferdowsi University of Mashhad, Mashhad, P.O. Box 917ry-1111, \\ Iran.
}

Received 13 February 2016; received in revised form 4 December 2016; accepted 19 December 2016

\section{KEYWORDS \\ Capital budgeting; Time horizon model; Goal programming; Fuzzy Analytic Hierarchy Process (FAHP); Construction industry.}

\begin{abstract}
Due to the increase of investments in construction projects and the lack of practical models in this area, developing new practical models is essential. In this paper, researchers suggest a new model in which (1) Its assumptions are adopted based on the real world, (2) Goal programming is used because of the soft nature of the budget constraints, and (3) Risk of variations in cash flows is considered. The presented model chooses the most profitable portfolio of projects and determines their respective financing resources, area under construction, and pre-sale and sale amounts for each period, such that the cumulative cash flow at the end of the time horizon is maximized. The Fuzzy Analytic Hierarchy Process (FAHP) is used to determine the weight of the objectives. The exact solution to the model is obtained using the ILOG CPLEX software. The presented solution seems efficient since it yields very small elapsed times to solve exactly the real-world-sized problems. Also, the sensitivity analysis is performed and the results are deliberately studied and analyzed. Parameters, such as pre-sale prices, mean, and variance of the sale price and construction costs, are among the highly sensitive parameters.

(C) 2018 Sharif University of Technology. All rights reserved.
\end{abstract}

\section{Introduction}

The construction industry is one of the most important industries in any country, since it absorbs vast investments and is one of the substantial needs of the community. Nevertheless, this industry suffers from huge amounts of capital wastes caused by poor and inefficient capital budgeting [1]. Compared to other industries, the absence of financial control and weak management has led to a set of undesirable and irreversible results. In addition, the bankruptcy level is significantly high which can be alleviated with a

\footnotetext{
*. Corresponding author.

E-mail addresses: se_et536@alumni.um.ac.ir (S. Etemadi); koosha@um.ac.ir (H.Koosha); msalari@ferdowsi.um.ac.ir (M. Salari)
}

doi: $10.24200 /$ sci. 2017.4436 better cash flow management procedure [2]. Cash flow analysis of construction projects is an important issue in construction industry [3]. Therefore, this paper is dedicated to the capital budgeting of construction companies due to the lack of applicable models in this area.

This research develops a model, which helps decision-makers in construction industry to select the most profitable investment opportunity from a pool of available opportunities and determine the proper financial resources at the right time. The data from a real construction company is used in order for the model to be more adaptive to the real world and to be able to quench the industry's expectations.

Capital budgeting is a process that allocates limited financial resources to the available projects and aims at maximizing the return on investment [4]. Capital budgeting is a major problem that manages the financial resources. This is usually a long-term 
problem involving risk complications and needs significant amounts of investment. The majority of capital budgeting decisions are irreversible. Therefore, applying proper capital budgeting models, leading into the right decisions on choosing the right projects at the right time, is crucial to the survival of the companies in their uncertain environment [5].

The first research on capital budgeting was reported by Lorie and Savage [6] with the goal of maximizing the Net Present Value (NPV). Weingartner [7] presented a mathematical programming model for the capital budgeting problem that maximizes cumulative cash at the end of the time horizon, known as horizon models. Unlike the NPV maximization approach, the model developed by Weingartner considers different financial resources with different interest rates and transfers each period's unused budgets to its next period. In addition, the consideration of possible loaning, borrowing, and different financing approaches is amongst the noteworthy characteristics of this model. Thus, it is very well adapting to the real-world situations; therefore, modeling the capital budgeting problem through the maximization of the cumulative cash at the end of a pre-specified time horizon is preferred to the maximization of the NPV [8].

However, Weingartner's time horizon model faces some critical issues. In particular, the presence of the hard budget constraints in the model is one of these issues. Considering each period's budget constraint as an internal functional constraint imposed by the management is more realistic than considering it as an external constraint imposed by the market [9]. Thus, one can consider the budget constraints as soft constraints and minimize the deviation from the ideal. To this end, goal programming is the most common and reputable method already suggested for such situations.

As in the literature, all the following researchers have presented their models: Taylor and Keown [10] for police department budgeting, Lawrence and Reeves [11] for an insurance company, Mukherjee and Bera [12] for India coal industry, and Thizy et al. [13] for a Canadian telecommunication company. In addition, Badri et al. [14] presented a binary goal-programming model for project selection in a healthcare institute. Vashishth et al. [15] proposed a binary goal programming model for the capital budgeting of a hospital. None of the aforementioned studies considers the loaning, borrowing, and different financing approaches with different interest rate options.

Goal programming model along with the Fuzzy Analytic Hierarchy Process (FAHP) is a supple tool to accomplish the goals under various constraints [16]. Hence, neither of them is adequate for considering the numerical and non-numerical information alone [17]. The FAHP prepares a relatively mature explanation of the decision process, including personal and imprecise judgments of the decision-makers [18]. Chang [19] presented the Extent Analysis Method for the FAHP in which triangular fuzzy numbers for pairwise comparisons are used. Other methods as Modified Digital Logic (MDL) and Fuzzy Decision-Making Trial and Evaluation Laboratory (FDEMATEL) are used to prioritize the importance of various criteria. Chaghooshi et al. [20] proposed the decision-making process of selecting the most suitable managers for projects using FDEMATEL method. Rathi et al. [21] developed a project selection approach to determining proper Six Sigma projects in automotive companies using the MDL method. Ghazimoradi et al. [22] proposed a model based on neural networks to anticipate the success of construction projects depending on the level of realization of success factors during the initial phase of a project. Tang and Chang [23] applied the goal programming and FAHP to a capital budgeting problem in a small car renting company. However, their model does not utilize the Weingartner's horizon model along with the cash flow of the investment opportunities as the criteria for optimal investment opportunity selection.

Another critical issue with the Weingartner's model is that it ignores risk and uncertainty. Though risk management and capital budgeting often need to be considered jointly [24], none of the aforementioned studies considers the uncertainty and risk of the projects seldom inevitable, especially in investmenttype projects.

The main goal of the portfolio optimization is to help the investor optimally allocate financial resources to the investment opportunities, such that the risk and uncertainty parameters are accounted for [25]. Risk and uncertainty can be considered as a Markowitz mean-variance model [26], Capital Asset Pricing Model (CAPM) [27,28,29], and Value at Risk (VaR) model [30]. Su and Huang [31] proposed a meanvariance capital budgeting model in which project parameters are regarded as random variables. Babaei et al. [32] formulated the portfolio optimization problem as a multi-objective mixed integer programming in which VaR is specified as the risk measure. Beraldi et al. [33] considered Conditional Value at Risk (CVaR) in their capital budgeting model. Khalili-Damghani and Taghavifard [34] proposed a multi-dimensional knapsack model for capital budgeting under uncertainty in which fuzzy set theory is applied.

Contrary to the Weingartner's time horizon model, in this article, budget constraints are considered soft and the capital budgeting problem for construction companies is modeled in the form of goal programming. FAHP is also used to determine the weight of the objectives.

In addition, we consider the risk in our model. 
Since the CAPM and VaR models need a number of difficult-to-estimate parameters in the case of construction companies, they do not seem suitable in this area. Hillier [35] evaluated risky investments by estimating the expected values and standard deviations of net cash flows for each alternative investment. Walls [36] defined risk as the standard deviation of returns (i.e., net present value) of the portfolio of assets. He pointed out that this measure is more precisely defined as a statistical measure of uncertainty. In this study, the risk is considered rather similar to the mean-variance model. The only difference here is that instead of the capital return, the cumulative cash flow at the end of the time horizon is used.

In this paper, we propose a capital budgeting model with considering the risk of projects in order to apply in the construction industry. In the model, we consider time value of money and the risk of the projects. Since the budget constraints are usually soft and multiple objectives are available in the real world, goal programming is applied to cope with this situation. Because the weights of goals in the model are determined by experts' estimations, the fuzzy analytic hierarchy process is used for an efficient estimation of the weights.

The rest of this paper is organized as follows. In the next section, the problem definition, modeling approach, and the suggested mathematical model are included. Section 3 is dedicated to designing and exactly solving a number of sample problems. The sensitivity analysis results of the model and interpretation of the results are presented in Section 4. Finally, conclusions and future research directions are provided in Section 5.

\section{Problem definition and modeling}

In this section, we develop a formal description of the problem. In particular, two models, including a single-objective mixed integer programming and a mixed integer goal programming model, are presented.

\subsection{Problem definition}

The problem is based on the data from a construction company. According to the geographical position of the projects and the municipality requirements, the maximum allowed construction area for each project is known. The scope of the projects is limited to construction of the residential and commercial units. The construction time of the projects varies between 24 to 30 months or 8 to 10 time periods, where each period consists of 3 months.

The construction costs can be categorized into two groups, including fixed and variable costs. The fixed cost is independent of the construction area, while variable costs depend on the construction area. The variable costs in the construction industry are usually higher than the fixed costs.

Financing of a project is possible through a set of resources including the capital from the investors, loans, and the pre-sale of some parts of the project. Two types of interest rates are considered. In particular, one is the interest rate of the bank, and the other is the lending interest rate for the cases to which the company lends money (external investment opportunities) and the return of the cash flows from the sale unit. At each time period, there is a limit on the maximum amount of money loaned from the bank. This bound is a pre-specified percent of the money from the investors up to that period.

\subsection{Model development}

To find the ideal values for risk and cash at the end of the time horizon, we suggest solving the singleobjective model. By solving the single-objective model, the range of the ideal values for the maximization of the cumulative cash at the end of the time horizon and an upper bound for the risk constraint are determined; both are considered as parameters of the goalprogramming model.

The model assumptions are as follows:

1. The unit material and equipment cost (price) are constants during the periods of construction;

2. The remaining area from the whole pre-sale of a project is sold equally in sale periods;

3. The lending (external investment) interest rate and the interest rate of the returning cash flows from sale are assumed the same;

4. The end of the time horizon, at which the sum of the cumulative cash is maximized, is considered as the final construction period.

\section{Parameters of the model}

$J \quad$ Set of projects

$I \quad$ Set of tools (equipment)

$L \quad$ Set of construction time periods

$N \quad$ End of the time horizon

$H \quad$ Set of sale time periods

$k \quad$ Number of sale periods

$n^{\prime} \quad$ The period at which the sum of all the cash flows up to that period must be positive without considering the time value of money, $n^{\prime}<N$

$f_{j} \quad$ Inflation rate for the selling price of one square meter of project $j$

$r_{l} \quad$ The interest rate of lending and returning the cash flows from sale (beyond the time horizon)

$r_{b} \quad$ Bank loan interest rate 
$\mu_{p_{j s}} \quad$ Mean sale price of one area unit of project $j$ in the first time period after the accomplishment of project $j$

$\sigma_{p_{j s}} \quad$ Sale price variance (fluctuations) of one unit area of project $j$ in the first time period after the accomplishment of project $j$ (risk measure of the project j)

$p_{j n} \quad$ Pre-sale price of project $j$ in period $n$ (for each area unit)

$F_{j n} \quad$ Fixed construction cost of project $j$ in period $n$

$m_{\text {jin }} \quad$ Required amount of material and equipment of type $i$ for project $j$ in period $n$

$c_{j i} \quad$ Unit cost of material and equipment of type $i$ for project $j$

$K_{j} \quad$ Maximum allowed construction area for project $j$

$M_{n} \quad$ Maximum available budget of investors in period $n$

$B_{1 n} \quad$ Maximum allowed bank-loan-type financing in period $n$

$\alpha_{j n} \quad$ Allowed pre-sale percentage of project $j$ in period $n$

$P \quad$ Risk constraint upper bound

$w_{g} \quad$ Penalty for the deviation of the cumulative cash in period $N$

$w_{n} \quad$ Penalty for the deviation of the budget constraint in period $n$

$w_{n^{\prime}} \quad$ Penalty for the deviation of the "sum of cash flow positivity up to $n^{\prime \prime}$ " constraint from the specified ideal

$G \quad$ The ideal cumulative cash in period $N$ $v_{j n}=\sum_{i=1}^{r} m_{j i n} c_{j i}$ Variable construction cost of project $j$ in period $n$

\section{Decision variables}

$x_{j} \quad$ Binary variable equals to 1 if project $j$ is selected and 0 otherwise

$y_{j} \quad$ Total construction area for project $j$

$v_{n} \quad$ Lending value (external investment) from period $n$ to $n+1$

$w_{1 n} \quad$ Loaned value of the bank from period $n$ to $n+1$

$w_{2 j n} \quad$ Pre-sale value of project $j$ in period $n$

$d_{g}^{-},\left(d_{g}^{+}\right) \quad$ Decision variable for negative (positive) cumulative cash deviation in period $N$ from the specified ideal

$$
\begin{aligned}
& d_{n}^{-},\left(d_{n}^{+}\right) \quad \text { Decision variable for negative (positive) } \\
& \text { budget constraint deviation in period } \\
& n \text { from the specified ideal } \\
& d_{n^{\prime}}^{-},\left(d_{n^{\prime}}^{+}\right) \quad \text { Decision variable for negative (positive) } \\
& \text { deviation of the "sum of cash flow } \\
& \text { positivity up to } n^{\prime \prime} \text { " constraint from the } \\
& \text { specified ideal }
\end{aligned}
$$

\subsubsection{Single objective model}

The non-linear programming model for the problem is as follows:

$$
\begin{aligned}
& \operatorname{Max} \sum_{j=1}^{|J|} \sum_{h=1}^{k} \frac{\left(1+f_{j}\right)^{h-1} \mu_{p_{j s}} \frac{\left(y_{j}-\sum_{n=0}^{N} w_{2 j n} / p_{j n}\right)}{k}}{\left(1+r_{l}\right)^{h}} \\
&+\nu_{N}-w_{1 N}, \\
& \sum_{j=1}^{|J|} \sum_{i=1}^{|I|} m_{j i 0} c_{j i} y_{j}+\sum_{j=1}^{|J|} F_{j 0} x_{j}+\nu_{0}-w_{10} \\
& \quad-\sum_{j=1}^{|J|} w_{2 j 0} \leq M_{0}, \\
& \sum_{j=1}^{|J|} \sum_{i=1}^{|I|} m_{j i n} c_{j i} y_{j}+\sum_{j=1}^{|J|} F_{j n} x_{j}-\left(1+r_{l}\right) \nu_{n-1}+\nu_{n} \\
& \quad+\left(1+r_{b}\right) w_{1, n-1}-w_{1 n}-\sum_{j=1}^{|J|} w_{2 j n} \leq M_{n}
\end{aligned}
$$

$\forall n \in L$,

$\sum_{j=1}^{|J|} \sum_{i=1}^{|I|} \sum_{n=0}^{n^{\prime}}\left(m_{j i n} c_{j i} y_{j}+F_{j n} x_{j}-w_{2 j n}\right) \leq 0$,

$\frac{1}{k^{2}} \sum_{j=1}^{|J|}\left(\frac{\left(1+r_{l}\right)^{k}-\left(1+f_{j}\right)^{k}}{\left(r_{l}-f_{i}\right)\left(1+r_{l}\right)^{k}}\right)^{2} \sigma_{p_{j s}}^{2}$

$$
\left(y_{j}-\sum_{n=0}^{N} w_{2 j n} / p_{j n}\right)^{2} \leq p
$$

$\left(y_{j}-\sum_{n=0}^{N} w_{2 j n} / p_{j n}\right) \geq 0 \quad \forall j \in J$,

$w_{1 n} \leq B_{1 n}, \quad \forall n \in L$,

$w_{2 j n} \leq \alpha_{j n} p_{j n} y_{j}, \quad \forall j \in J, n \in L$,

$y_{j} \leq K_{j} x_{j}, \quad \forall j \in J$,

$x_{j} \in\{0,1\}, \quad \forall j \in J$, 


$$
\begin{aligned}
& y_{j} \geq 0, \quad \forall j \in J, \\
& \nu_{n} \geq 0, \quad \forall n \in L, \\
& w_{1 n} \geq 0, \quad \forall n \in L, \\
& w_{2 j n} \geq 0, \quad \forall j \in J, n \in L .
\end{aligned}
$$

The objective function (1) maximizes the expected cumulative cash in period $N$. It comprises three terms. The first term is the sum of all sales revenues of all selected projects considering time value of money at the $N$ th period. In order to consider the time value of money, the sales revenue of each project in each sales period is discount by $r_{l}$ interest rate to find its value at the end of $N$ th period. The second term is amount of lending value (external investment) at the end of horizon, and the last term is the amount of borrowed value at the end of horizon. Constraints (2) and (3) express the maximum amount of budget from the investors in each construction period. Constraint (4) ensures that the sum of all input and output cash flows of all projects up to period $n^{\prime}$ is positive so that, up to $n^{\prime}$, the income of the projects could cover their costs. Constraint (5) ensures that the cumulative cash variance (the measure of project risk) in period $N$ is less than the maximum bearable risk. The variance of the objective function is considered as the risk constraint. Constraint (6) ensures that the sum of pre-sale and sold areas is no more than the total construction area of each project. Constraint (7) indicates the maximum allowed bank-loan-type financing. Constraint (8) restricts the maximum allowed pre-sale and sale area of each project in each period. Constraint (9) shows the maximum allowed construction area of all projects. Constraint (10) shows that $x_{j} s$ are binary variables and Constraints (11) to (14) give the non-negativity constraints.

Figure 1 demonstrates a timeline of the cash flow of project whose sales period, construction period, and period $n^{\prime}$, in which the accumulated budget should be positive, are specified.

\subsubsection{The goal programming model}

The goal programming model, by taking into account Constraints (5) to (14), is as follows:

$$
\begin{aligned}
& \operatorname{Min} w_{g} d_{g}^{-}+\sum_{n=0}^{N} w_{n} d_{n}^{+}+w_{n} d_{n^{\prime}}^{+} \\
& \sum_{j=1}^{|J|} \sum_{h=1}^{k} \frac{\left(1+f_{j}\right)^{h-1} \mu_{p_{j s}} \frac{\left(y_{j}-\sum_{n=0}^{N} w_{2 j n} / p_{j n}\right)}{k}}{\left(1+r_{l}\right)^{h}} \\
& \quad+\nu_{N}-w_{1 N}+d_{g}^{-}-d_{g}^{+}=G
\end{aligned}
$$

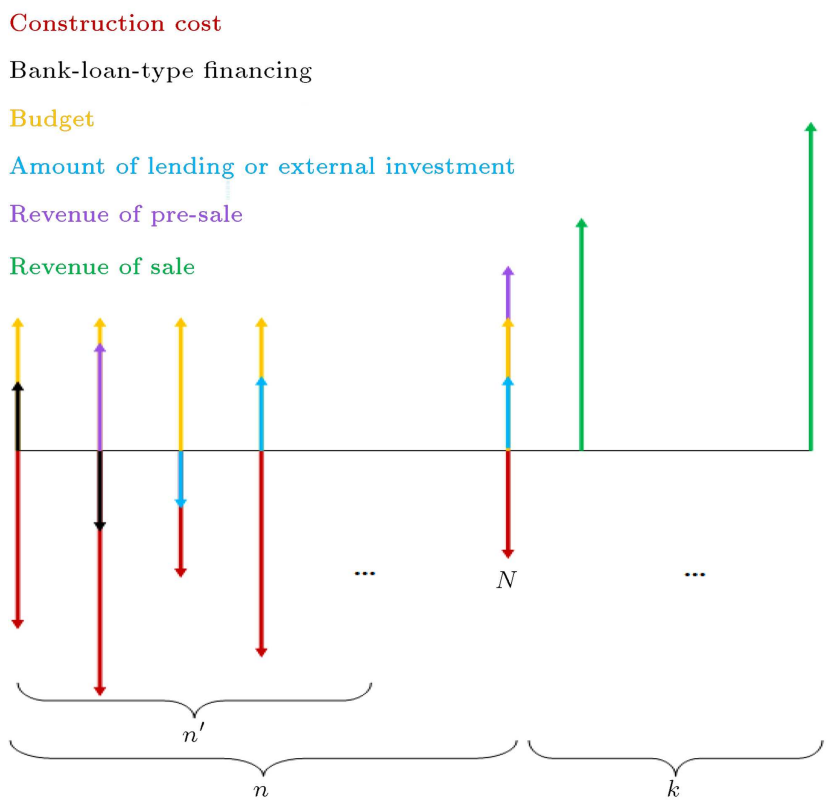

Figure 1. Timeline of the project.

$$
\begin{aligned}
& \sum_{j=1}^{|J|} \sum_{i=1}^{|I|} m_{j i 0} c_{j i} y_{j}+\sum_{j=1}^{|J|} F_{j 0} x_{j}+\nu_{0}-w_{10}-\sum_{j=1}^{|J|} w_{2 j 0} \\
& \quad+d_{0}^{-}-d_{0}^{+}=M_{0}, \\
& \sum_{j=1}^{|J|} \sum_{i=1}^{|I|} m_{j i n} c_{j i} y_{j}+\sum_{j=1}^{|J|} F_{j n} x_{j}-\left(1+r_{l}\right) \nu_{n-1}+\nu_{n} \\
& \quad+\left(1+r_{b}\right) w_{1, n-1}-w_{1 n}-\sum_{j=1}^{|J|} w_{2 j n} \\
& \quad+d_{n}^{-}-d_{n}^{+}=M_{n} \quad \forall n \in L
\end{aligned}
$$

$$
\begin{aligned}
& \sum_{j=1}^{|J|} \sum_{i=1}^{|I|} \sum_{n=0}^{n^{\prime}}\left(m_{j i n} c_{j i} y_{j}+F_{j n} x_{j}-w_{2 j n}\right) \\
& \quad+d_{n^{\prime}}^{-}-d_{n^{\prime}}^{+}=0 .
\end{aligned}
$$

The objective Function (15) minimizes the sum of all deviations from the ideal values. Essentially, it minimizes the negative deviation from the expected cumulative cash in period $N$, the sum of positive deviations from the ideal budget of the investors in each period, and the positive deviation of the "sum of cash flow positivity up to $n^{\prime \prime}$ constraint from the specified ideal. Constraint (16) expresses the expected cumulative cash in period $N$. Constraints (17) and (18) determine the maximum budget of investors during each construction period. Constraint (19) ensures that the sum of all input and output cash flows up to period 
$n^{\prime}$ is positive so that the projects' income could cover their costs up to $n^{\prime}$.

\section{Application of the model}

To evaluate the performance of the proposed models, a set of 9 sample problems is designed. In addition, the weight of the objectives is measured through the Fuzzy Analytic Hierarchy Process (FAHP). The singleobjective model along with the goal-programming model is solved using the ILOG CPLEX 12.1.

\subsection{Data development and parameter adjustment}

A set of 9 sample problems with time horizon belonging to $\{8,9,10\}$ periods and 10,15 , and 20 projects is designed. The corresponding values of parameters are reported in Table 1.

The mean building sale price inflation is calculated based on the geometric mean Eq. (20) in which $a_{1}$ and $a_{N}$ are the sale prices in the first and $N$ th periods, respectively. Different sale price inflation rates are assigned to different projects based on the place's growth potential (see Table 1):

$$
f=\sqrt[N]{\frac{a_{N}}{a_{1}}}-1=0.054 .
$$

All building sale prices for different years are inflated with a 0.054 inflation rate and transferred to the final period. In order to calculate the mean building sale price and the building sale price variance, Eqs. (21) and (22) are utilized:

$$
\begin{aligned}
\mu_{p_{j s}} & =\sum_{n=1}^{n=N} \frac{a_{n}(1+f)^{N-n}}{N}=83.037 \\
\sigma_{p_{j s}}^{2} & =\frac{\sum_{n=1}^{n=N}\left(\alpha_{n}(1+f)^{N-n}-\mu_{p_{j s}}\right)^{2}}{N-1}=276.475 .
\end{aligned}
$$

The parameters such as $f_{j}$, interest rates, $B_{1 n}, p_{j n}$, $\mu_{p j s}$, and $\sigma_{p j s}$ are determined based on market and bank situations; numbers of construction and sale period are determined based on real situations of the construction company. Through a variety of construction projects, the exact and specific data for other parameters, such as $K_{j}$, fixed and variable costs, are not available because of the poor accounting methods, but the ranges for each of them are calculated according to the rough estimates. We use several data by considering random distribution around the calculated parameter to assess validation of the model and evaluate whether the output is influenced by a specific data or not.

Since risk of investments can be evaluated by estimating standard deviations of net cash flows for each alternative investment and such a measure is more precisely defined as a statistical measure of uncertainty $[35,36]$, therefore, in this paper, the projects' risk is considered in the same way. Moreover, because the exact value of the risk upper bound $(p)$ is not available, one can solve the single-objective model through eliminating the risk (the more profitable the project, the higher the risk or the variance), and then place all parameters and obtained variables in the risk constraint and calculate the maximum value for it. Thereafter, based on the company's policy and its risk-taking level, one can adjust an upper-bound risk constraint equal to a proportion of the maximum calculated value (e.g., 0.0, 0.3, 0.5, 0.8, etc.). The single-objective model considering the risk constraint is solved, whose optimal value and associated risk are considered as the ideal and the upper-bound risk constraints in the goal programming model, respectively.

\subsection{Objectives' weight in the goal programming model}

In order to run the Fuzzy Analytic Hierarchy Process (FAHP) and determine the weights of the introduced

Table 1. Values of common parameters in sample problems.

\begin{tabular}{cc}
\hline Parameters & Values \\
\hline$k$ & 4 \\
$r$ & 4 \\
$r_{l}$ & 0.05 \\
$r_{b}$ & 0.0625 \\
$\alpha_{j n}$ & 0.5 \\
$B_{1 n}$ & $80 \%$ of the sum of $M_{n}$ up to that period \\
$m_{j i n}$ & A random value from $(0-2)$ \\
$k_{j}$ & A random value from $(10,000-15,000)$ square meter \\
$f_{j}$ & A random value from $(0.027-0.081)$ \\
$\mu_{p j s}$ & A random value from $(38-80)$ \\
$c_{j i}$ & e.g., $|I|=4$, A random value from $(0.1-0.3),(0.3-0.5),(0.5-0.7),(0.7-0.9)$ \\
$M_{n}$ & A random value from $(50000-70000)$, e.g. 52,910 \\
\hline
\end{tabular}


Table 2. Fuzzy numbers for pairwise comparisons.

\begin{tabular}{cc}
\hline Equal preference & $(1,1,1)$ \\
Medium preference & $(1 / 2,1,3 / 2)$ \\
Strong preference & $(1,3 / 2,2)$ \\
Very strong preference & $(3 / 2,2,5 / 2)$ \\
Absolute preference & $(2,5 / 2,3)$ \\
\hline
\end{tabular}

objectives in the proposed model, the extent analysis method [19] is used. The applied fuzzy numbers [37] are given in Table 2. Pairwise comparisons between the objectives are based on the decision-maker's opinions (Weight 1 in Table 3 ). Other weights in Table 3 are obtained according to sensitivity analysis performed on different weights.

\subsection{Application of the single-objective and goal programming models}

The exact solutions of the single-objective and goalprogramming models are obtained using the ILOG CPLEX 12.1 software, which is capable of solving quadratic problems. The CPLEX running time varies from a few hundredth of a second to a few seconds. The solution procedure seems reasonable since the capital budgeting problem is in the category of the strategic problems and time is not a matter of concern.

The output of the single-objective model determines the projects that own the cumulative cash at the end of the time horizon, construction area, and pre-sale and sale amounts of each project for each period. Also, the amount of money borrowed and lent for external investment is determined. A project is not selected if it is not profitable enough. In other words, its profit is less than that from the external investment. The lending and borrowing activities cannot occur simultaneously in the same period.

The set of problems with $0.0,0.3,0.5$, and 0.8 risk coefficients is solved. Any decrease in the risk coefficient decreases the amounts of sale and increases the amounts of pre-sale, while the profit at the end of the time horizon decreases. A risk coefficient equal to
0.0 results in the pre-sale of all the selected projects and the amounts of their sale remains zero.

In problems with similar projects, increasing the number of construction periods in order to cover the costs leads to an increase in the amount of pre-sale and a decrease in the amounts of sale. In some cases, any increment in the number of construction periods might cause the project to become unprofitable. If none of the projects is profitable under any circumstances, the external investment option becomes preferable.

\section{Analysis and discussion}

In this section, the sensitivity analysis of both singleobjective and goal-programming models is discussed.

\subsection{Sensitivity analysis of the parameters of the single-objective model}

By increasing the corresponding values of $F_{j n}, v_{j n}$, $r_{b}$, and or $r_{l}$ up to the point that the risk becomes zero, the values of the objective function decrease because the expenditure is more than the revenue of projects; moreover, the risk parameter decreases because the amounts of pre-sale to cover the costs increase. Increasing the values of $M_{n}, K_{j}, p_{j n}, \mu_{p j s}$, $\sigma_{p j s}$, and/or $f_{j}$ will increase the corresponding values of the objective function and risk parameter (the more profitable the project, the higher its risk). As an example, the results of changing the values of $r_{b}$ on objective function values in Figure 2 and on risk values are depicted in Figure 3.

\subsection{External investment analysis under different parameter values in the single-objective model}

Decreasing the corresponding values of $K_{j}, p_{j n}, \mu_{p j s}$, and $\sigma_{p j s}$ and increasing the corresponding values of $F_{j n}$, and $v_{j n}$ show that, at a point of change, all the projects become unprofitable, or a smaller number of them remain in the profitability zone, while this causes all or parts of the available budget to stay untouched. In this case, all or a portion of the unused budget

Table 3. Set of 4 weights for the 8 periods time horizon problem.

\begin{tabular}{lcccc}
\hline \multicolumn{1}{c}{ Objectives } & Weight 1 & Weight 2 & Weight 3 & Weight 4 \\
\hline Cumulative cash at the end of the time horizon & 0.16563 & 0.16563 & 0.16563 & 0.16563 \\
Budget constraint of period 0 & 0.15234 & 0.03790 & 0.15234 & 0.15234 \\
Budget constraint of period 1 & 0.13921 & 0.06200 & 0.13921 & 0.13921 \\
Budget constraint of period 2 & 0.12587 & 0.09044 & 0.12587 & 0.12587 \\
Budget constraint of period 3 & 0.11672 & 0.10988 & 0.03790 & 0.11672 \\
Budget constraint of period 4 & 0.10988 & 0.11672 & 0.10988 & 0.10988 \\
Budget constraint of period 5 & 0.09044 & 0.12587 & 0.09044 & 0.03790 \\
Budget constraint of period 6 & 0.06200 & 0.13921 & 0.06200 & 0.06200 \\
Budget constraint of period 7 & 0.03790 & 0.15234 & 0.11672 & 0.09044 \\
\hline
\end{tabular}




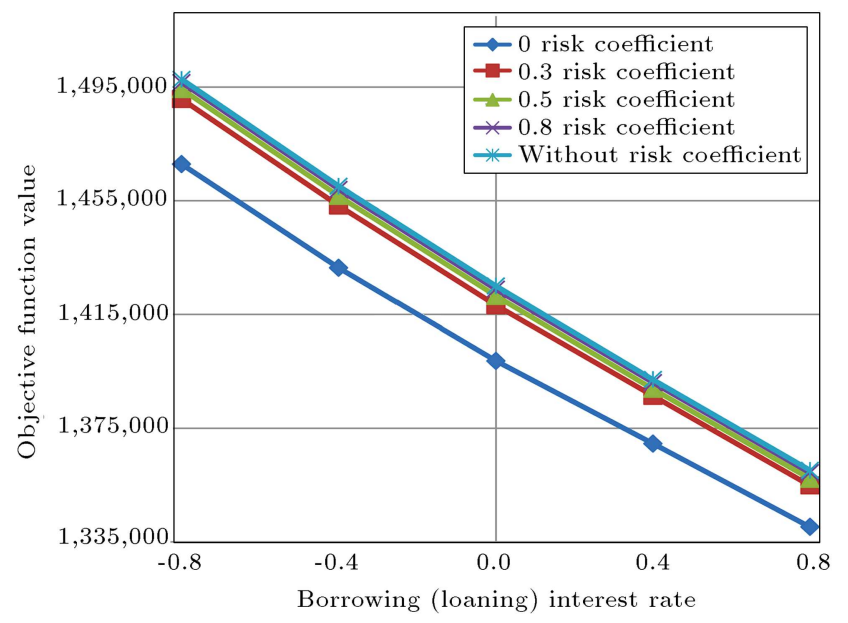

Figure 2. Objective function value changes under different $r_{b}$ values in different risk levels.

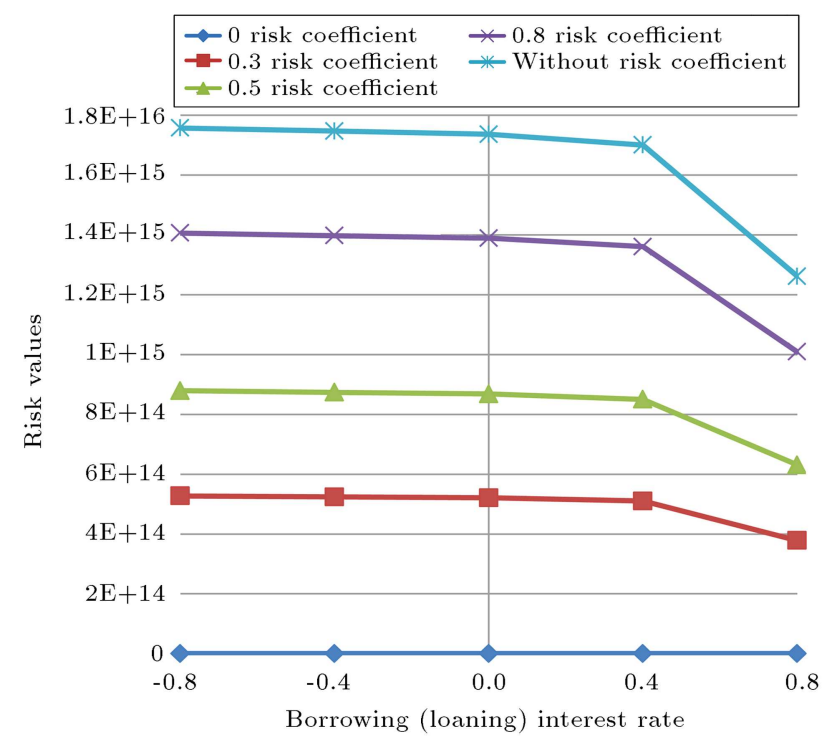

Figure 3. Risk changes under different $r_{b}$ values in different risk levels.

is invested in the external investment options; thus, from a specific period forward, $v_{n}$ variables take values constantly.

The effects of $K_{j}, p_{j n}, \mu_{p j s}, \sigma_{p j s}, F_{j n}$, and $v_{j n}$ on profitability and the investment policies of the company are way more profound than the effects of $M_{n}, r_{b}$, $r_{l}$, and $f_{j}$; hence, they can be labeled as the highsensitivity parameters of the model.

\subsection{Sensitivity analysis of the parameters of the goal programming model}

In order to perform sensitivity analysis on the parameters of the goal programming model, a problem with 8 periods and 10 projects is selected. First, the problem is solved with a set of risk coefficients equal to $0.0,0.3$, 0.5 , and 0.8 and with no change in parameter values in the single-objective model. Then, the optimal value of the objective function is assumed as the ideal in the goal programming model with its associated risk. All the analyses are based on these calculated ideals for the cumulative cash at the end of the time horizon and their associated risk upper bound. A set of weights or priorities for the cumulative cash at the end of the time horizon and the budget constraints is considered (Table 3).

By increasing the corresponding values of $G, F_{j n}$, $v_{j n}, r_{b}$, and/or $r_{l}$ or decreasing the corresponding values of $M_{n}, K_{j}, p_{j n}, \mu_{p j s}, \sigma_{p j s}$, and/or $f_{j}$, when the cumulative cash at the end of the time horizon has the highest priority, in order to achieve the ideal value, the budget increases for the period that has the lowest priority budget constraint. The amounts of increase in period 0 are less than period 3 , period 3 is less than period 5 , and so on. This is because of the time value of money, meaning that the same amount of money has different values in different periods due to its potential earning capacity.

In the case where the ideal value of the cumulative cash objective at the end of the time horizon is less than the value of the single-objective model, it is perceived that the projects are risk-free and the ideal is realized with no deviation from the budget constraint ideals.

By increasing the corresponding values of $G, F_{j n}$, and/or $v_{j n}$ or decreasing the corresponding values of $K_{j}\left(p_{j n}, \mu_{p j s}, \sigma_{p j s}\right)$ and/or $M_{n}$, while the associated budget of period 0 is increased to achieve the ideal value of cumulative cash at the end of horizon time objective, the sale amounts of projects would increase and their pre-sale amounts decrease, because costs of the projects can be covered by surplus budget; further, in the case where more projects are profitable, these projects would be selected; otherwise, the surplus budget would be spent on external investments. While the associated budget of another period is increased, the pre-sale amounts of all projects change, and in some cases, the amounts of sale increase or the surplus budget is spent on external investments.

The amounts of only pre-sale decrease and those of sale increase by increasing the corresponding values of $r_{b}$ or $r_{l}$ and/or decreasing the value of $f_{j}$, provided that the budget of each period is increased so that the ideal value of the cumulative cash at the end of the time horizon objective can be realized. In addition, surplus budget would not be spent on external investment because these are not highly sensitive parameters. The results of changes in $r_{b}$ are depicted in Figures 4 and 5 .

\subsection{Comparing the results}

In the goal-programming model, while the "cumulative cash at the end of the time horizon" has the highest priority, one can increase the budget for the period that has the lowest priority budget constraint by increasing the value of $G$ so that the ideal objective can be achieved. On the other hand, in the single-objective 


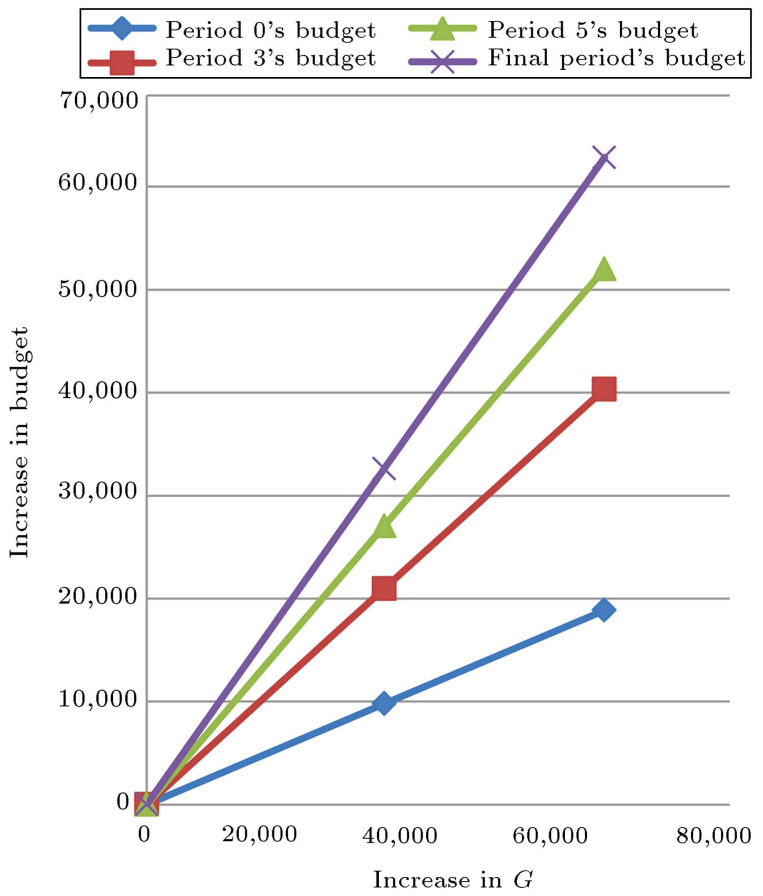

Figure 4. Increase in each period's budget to realize $G$ (with the increase in $r_{b}$ ); a 0.5 risk coefficient.

model, any deviation from the budget constraints for the purpose of achieving more profit is not possible, because they are considered as hard constraints. In fact, it is possible that the companies' favorable profit level is higher than the calculated value in the singleobjective model, and the company is able, to some extent, to increase the budget of each period. In this case, the single-objective model does not suffice and

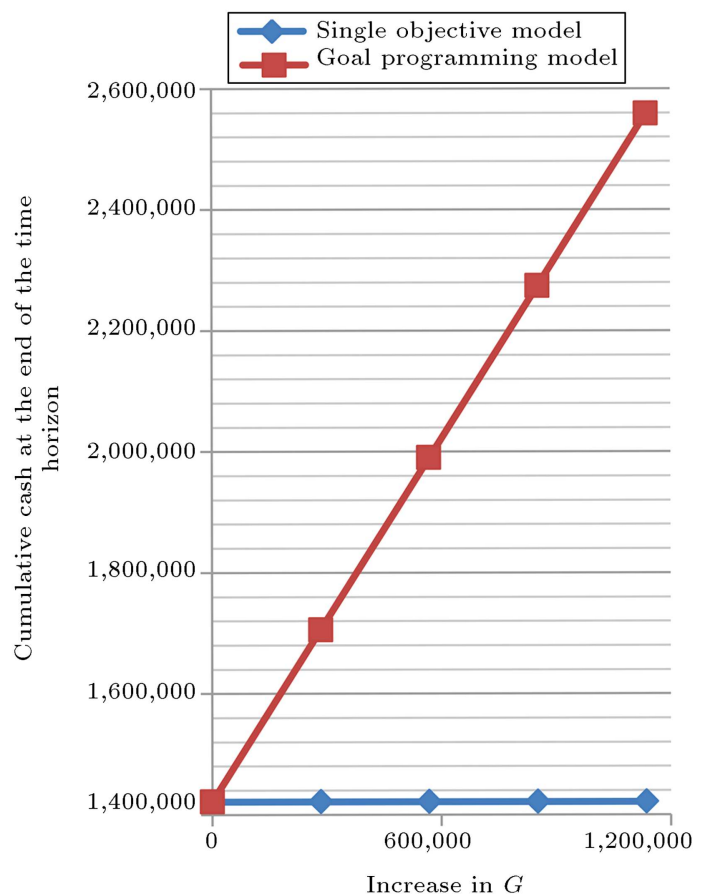

Figure 6. Comparing the results of the single-objective and goal programming models with the increase in $G$; a 0.5 risk coefficient.

the goal programming model is suitable to reach the specified profit level (Figure 6).

\section{Conclusions}

In this research, the capital budgeting problem for the case of a construction company is modeled. Consid-

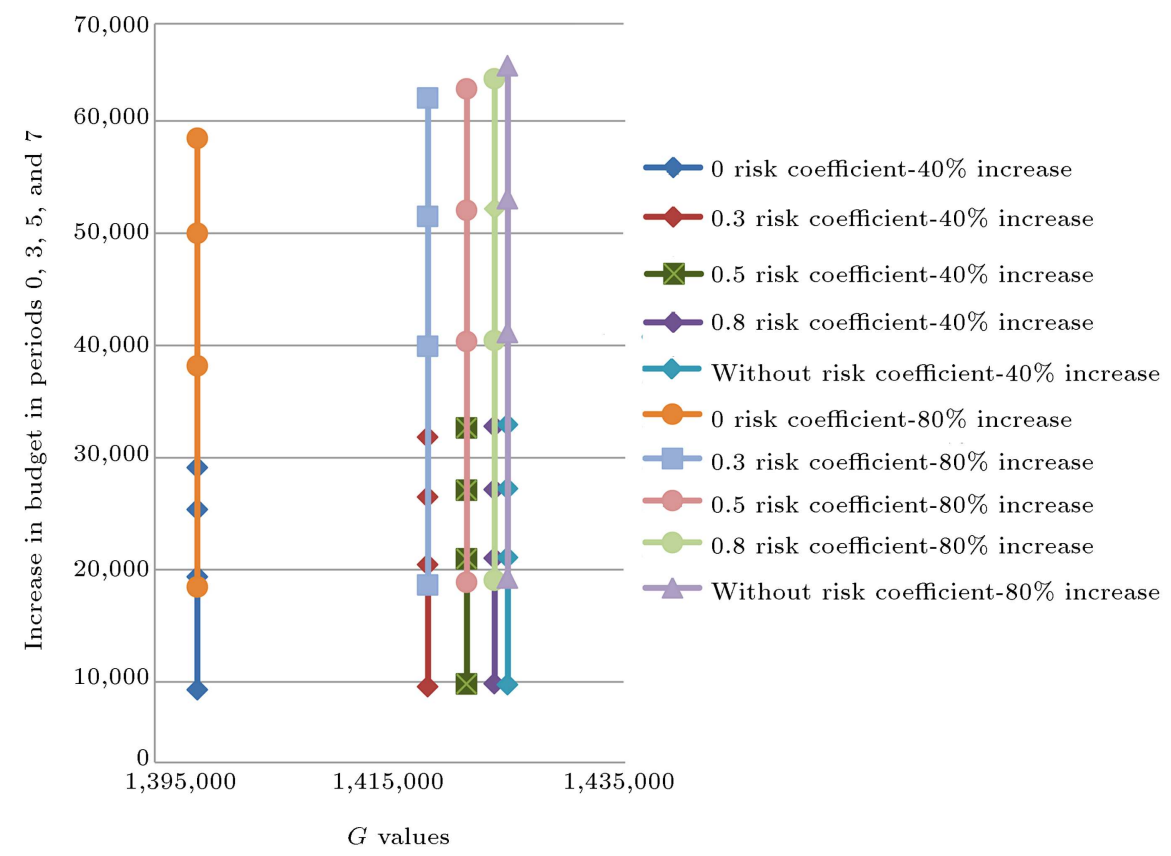

Figure 5. Increase in each period's budget to realize $G$ (with the increase in $r_{b}$ ) in different risk levels. 
ering the time value of money and different financial resources with different interest rates in the modeling is of great importance, which is one of the advantages of the presented models in this paper.

Since the real-world budget constraints are soft, goal programming is used to model the problem. In fact, in the goal programming model, one can modify the cumulative cash at the end of the time horizon to be set equal to the company's favorable value, so that the surplus budget of each period can be assigned and the specified ideal achieved. In this research, the FAHP approach is utilized and the risk of the projects is taken into account. The exact solutions of the models are obtained using the ILOG CPLEX.

The sensitivity analysis for both models is performed. Parameters, including pre-sale prices, mean and variance of the sale price, fixed and variable construction costs, and maximum allowed area under construction of the project, are among the highly sensitive parameters, meaning that any change in these parameters would affect the whole investment policy of the company. In addition, a change in these parameters, in some cases, increases the possibility of these projects to become unprofitable, while making the external investment a better option.

Since no particular model is presented for capital budgeting in the construction industry and the presented model in this article is based on the real circumstances of construction companies, it helps the construction companies in many ways, such as financial planning, selection of optimal investment opportunities, and choosing financial resources. Furthermore, the presented model considers the risk parameter as a constraint; therefore, the profit calculation at the end of the time horizon becomes more realistic.

A future research direction is modeling the problem such that features, such as the building characteristics and their quality levels, are added. Further, pre-sale prices and construction costs can be considered uncertain. Further, the uncertainty or risk minimization can be considered as an objective in the goal programming model, and one can consider special distribution function for the amount of selling at each sales period.

\section{References}

1. Famakin, I.O. and Saka, N. "Evaluation of the capital budget planning practice of contractors in the construction industry", Journal of Building Performance, 2(1), pp. 26-32 (2011).

2. Mutti, C.D.N. and Hughes, W. "Cash flow management in construction firms", Presented at 18th Annual ARCOM. Conf., Association of Researchers in Construction Management, University of Northumbria, $\mathbf{1}$, pp. 23-32 (2002).
3. Aziz, R.F. "Optimizing strategy for repetitive construction projects within multi-mode resources", Alexandria Engineering Journal, 52(1), pp. 67-81 (2013).

4. Zhang, Q., Huang, X., and Tang, L. "Optimal multinational capital budgeting under uncertainty", Computers \& Mathematics with Applications, 62(12), pp. 4557-4567 (2011).

5. Periasamy, P., A Textbook of Financial Cost and Management Accounting, Himalaya Publishing House (2010).

6. Lorie, J.H. and Savage L.J. "Three problems in rationing capital", The Journal of Business, 28(4), pp. 229-239 (1955).

7. Weingartner, H.M., Mathematical Programming and the Analysis of Capital Budgeting Problems, Englewood Cliffs. N. J.:Prentice-Hall, Inc (1963).

8. Park, C.S. and Sharp-Bette, G.P., Advanced Engineering Economics, New York: Wiley (1990).

9. Weingartner, H.M. "Capital rationing: An authors in search of a plot", The Journal of Finance, 32(5), pp. 1403-1431 (1977).

10. Taylor, B.W. and Keown, A.J. "A mixed-integer goal programming model for capital budgeting within a police department", Computers, Environment and Urban System, 6(4), pp. 171-181 (1981).

11. Lawrence, K.D. and Reeves, G.R. "A zero-one goal programming model for capital budgeting in a property and liability insurance company", Computers \& Operations Research, 9(4), pp. 303-309 (1982).

12. Mukherjee, K. and Bera, A. "Application of goal programming in project selection decision - A case study from the Indian coal mining industry", European Journal of Operational Research, 82(1), pp. 18-25 (1995).

13. Thizy, J.M., Pissarides, S., Rawat, S., and Lane, D.E., Interactive Multiple Criteria Optimization for Capital Budgeting in a Canadian Telecommunications Company, Springer Berlin Heidelberg, pp. 128-147 (1996).

14. Badri, M.A., Davis, D., and Davis, D. "A comprehensive 0-1 goal programming model for project selection", International Journal of Project Management, 19(4), pp. 243-252 (2001).

15. Vashishth, T.K., Babu, G.R., and Singh, R.K. "Capital Budgeting In Hospitals-A Case Study", International Journal of Advanced Research in Computer Science and Software Engineering, 2(6), pp. 87-92 (2012).

16. Ghosh D. and Roy, S. "A decision-making framework for process plant maintenance", European Journal of Industrial Engineering, 4(1), pp. 78-98 (2010).

17. Badri, M.A. "Combining the analytic hierarchy process and goal programming for global facility locationallocation problem", International Journal of Production Economics, 62(3), pp. 237-248 (1999). 
18. Ribeiro, R.A. "Fuzzy multiple attribute decision making: a review and new preference elicitation techniques", Fuzzy Sets and Systems, 78(2), pp. 155-181 (1996).

19. Chang, D.Y. "Applications of the extent analysis method on fuzzy AHP", European Journal of Operational Research, 95(3), pp. 649-655 (1996).

20. Chaghooshi, A., Arab, A., and Dehshiri, S. "A fuzzy hybrid approach for project manager selection", Decision Science Letters, 5(3), pp. 447-460 (2016).

21. Rathi, R., Khanduja, D., and Sharma, S. "A fuzzy MADM approach for project selection: a six sigma case study", Decision Science Letters, 5(2), pp. 255268 (2016).

22. Ghazimoradi, M., Kheyroddin, A., and Rezayfar, O. "Diagnosing the success of the construction projects during the initial phases", Decision Science Letters, 5(3), pp. 395-406 (2016).

23. Tang, Y.C. and Chang, C.T. "Multicriteria decisionmaking based on goal programming and fuzzy analytic hierarchy process: An application to capital budgeting problem", Knowledge-Based Systems, 26, pp. 288-293 (2012).

24. Ai, J. and Wang, T. "Enterprise Risk Management and Capital Budgeting under Dependent Risks: An Integrated Framework", 2012 Enterprise Risk Management Symposium, April 18-20, pp. 1-6 (2012).

25. Calafiore, G.C. "Multi-period portfolio optimization with linear control policies", Automatica, 44(10), pp. 2463-2473 (2008).

26. Markowitz, H. "Portfolio selection", The Journal of Finance, 7(1), pp. 77-91 (1952).

27. Lintner, J. "The valuation of risk assets and the selection of risky investments in stock portfolios and capital budgets", The Review of Economics and Statistics, 47(1), pp. 13-37 (1965).

28. Sharpe, W.F. "A linear programming algorithm for mutual fund portfolio selection", Management Science, 13(7), pp. 499-510 (1967).

29. Sharpe, W.F., Portfolio Theory and Capital Markets, New York: McGraw-Hill College (1970).

30. Linsmeier, T.J. and Pearson, N.D. "Risk measurement: An introduction to value at risk", Working paper University of Illinois at Urbana-Champain (1996).

31. Su, X.L. and Huang, X.X. "Mean-variance model for optimal multinational project adjustment and selection", In Applied Mechanics and Materials, 380, pp. 4809-4814, (2013).

32. Babaei, S., Sepehri, M.M., and Babaei, E. "Multiobjective portfolio optimization considering the dependence structure of asset returns", European Journal of Operational Research, 244(2), pp. 525-539 (2015).

33. Beraldi, P., Violi, A., De Simone, F., Costabile, M., Massabò, I., and Russo, E. "A multistage stochastic programming approach for capital budgeting problems under uncertainty", IMA Journal of Management Mathematics, 24(1), pp. 89-110 (2013).
34. Khalili-Damghani, K. and Taghavifard, M. "Solving a bi-objective project capital budgeting problem using a fuzzy multi-dimensional knapsack", J. Ind. Eng. Int., 7(13), pp. 67-73 (2011).

35. Hillier, F.S. "The derivation of probabilistic information for the evaluation of risky investments", Management Science, 9(3), pp. 443-457 (1963).

36. Walls, M.R. "Combining decision analysis and portfolio management to improve project selection in the exploration and production firm", Journal of Petroleum Science and Engineering, 44(1), pp. 55-65 (2004).

37. Tolgaa, E., Demircana, M.L., and Kahraman, C. "Operating system selection using fuzzy replacement analysis and analytic hierarchy process", International Journal of Production Economics, 97(1), pp. 89-117 (2005).

\section{Biographies}

Sepideh Etemadi received the BSc degree in Industrial Engineering from Bahonar University of Kerman and MSc degree in the same field from Ferdowsi University of Mashhad. Her research interests lie in the project portfolio selection, capital budgeting and optimization. She has presented papers in the 7 th International Conference of Iranian operations research society, 12th International Conference on Industrial Engineering, and International Conference on Industrial Engineering and Management on these subjects.

Hamidreza Koosha received his BSc and MSc degrees in Industrial Engineering from Sharif University of Technology and his PhD degree in Industrial Engineering from Tarbiat Modares University. He is an Assistant Professor in Industrial Engineering at Ferdowsi University of Mashhad. His main research interests include Mathematical modeling and data analytics for customer relationship management and project portfolio selection. His publications appear in books and journals such as Management Decision and Journal of modelling in management.

Majid Salari received the BSc and MSc degrees in Applied Mathematics from the Ferdowsi University of Mashhad, Iran in 2004 and 2006, respectively. In addition, he has $\mathrm{PhD}$ in Automations and Operations Research from the University of Bologna, Italy in 2010. In 2010, he joined the Department of Industrial Engineering, Ferdowsi University of Mashhad, as an Assistant Professor, and became an Associate Professor in 2016. His current research interests include combinatorial optimization, applied operation research, evolutionary computation, heuristic search, logistics, distribution, and vehicle routing. 